Check for updates

Cite this: RSC Adv., 2017, 7, 20398

Received 15th January 2017

Accepted 22nd March 2017

DOI: $10.1039 / c 7 r a 00632 b$

rsc.li/rsc-advances

\section{Sulfur doped graphene as a promising metal-free electrocatalyst for oxygen reduction reaction: a DFT-D study $\dagger$}

\author{
Zhansheng Lu, (D) ab Shuo Li, ${ }^{a}$ Chuang Liu, ${ }^{a}$ Chaozheng He, ${ }^{c}$ Xinwei Yang, ${ }^{a}$ \\ Dongwei $\mathrm{Ma}^{\mathrm{d}}$ Guoliang $\mathrm{Xu}^{\mathrm{a}}$ and Zongxian Yang*ae
}

\begin{abstract}
As an efficient metal-free catalyst, graphene doped with heteroatoms is highly active in promoting electrochemical oxygen reduction reaction (ORR). The detailed kinetic and thermodynamic behaviors of the entire ORR process on sulfur doped monovacancy graphene (SGV), as well as the original mechanism are investigated by the dispersion-corrected density function theory (DFT-D) calculations. It is found that the $\mathrm{SG}_{V}$ is rather stable and the sulfur dopant is probably the active center. There are two proposed ORR pathways by kinetic process: the dissociation of $\mathrm{OOH}$ and the hydrogenation of $\mathrm{OOH}$ with the ratedetermining steps of $0.75 \mathrm{eV}$ and $0.62 \mathrm{eV}$, respectively. And the Gibbs free energy diagram of the entire ORR indicates that the dissociation of $\mathrm{OOH}$ is precluded, because the process of reduction step of $\mathrm{O}$ into $\mathrm{OH}$ is endothermic, while the hydrogenation of $\mathrm{HOOH}$ is the most favorable pathway even at high potential of $0.86 \mathrm{~V}$. Our DFT-D simulation suggests that the $\mathrm{SG}_{V}$ would be an efficient electrocatalyst for ORR.
\end{abstract}

\section{Introduction}

The energy-conversion efficiency of low-temperature fuel cells (FCs) is mainly limited by the slow kinetics of the oxygen reduction reaction (ORR) on cathode. ${ }^{\mathbf{1 , 2}}$ The most effective cathodes of the commercial FCs is Pt and its alloys. ${ }^{3}$ Given the high cost, low abundance and poor durability of the Pt-based catalysts in FCs, non-precious metals cathodes or metal-free carbon-based cathodes have sparked worldwide interest in very recent years owing to their low cost, environmental friendliness, outstanding activity and stability. ${ }^{4-9}$ The cheap and stable graphene-based materials doped with heteroatoms, ${ }^{\mathbf{1 0}}$ such as nitrogen, ${ }^{11,12}$ phosphorus, ${ }^{13,14}$ and their mixtures, ${ }^{15-17}$ present high catalytic activity and selectivity for ORR. The detailed kinetic behaviors and mechanisms of the entire ORR process on the modified graphene, such as phosphorus doped graphene, ${ }^{18,19}$ nitrogen doped graphene, ${ }^{20,21}$ boron doped graphene, ${ }^{22} \mathrm{MnN}_{4}$ embedded graphene, ${ }^{23}$ and $\mathrm{FeN}_{4}$ embedded

${ }^{a}$ College of Physics and Materials Science, Henan Normal University, Xinxiang 453007 , China. E-mail: yzx@henannu.edu.cn

${ }^{b}$ Department of Physics and Astronomy, University of California, Irvine, CA 926974575, USA

${ }^{c}$ College of Physics and Electronic Engineering, Nanyang Normal University, Nanyang 473061, China

${ }^{d}$ School of Physics, Anyang Normal University, Anyang 455000, China

${ }^{e}$ Collaborative Innovation Center of Nano Functional Materials and Applications, Kaifeng, China

† Electronic supplementary information (ESI) available. See DOI: 10.1039/c7ra00632b graphene, ${ }^{24,25}$ have been revealed successfully through density functional theory (DFT) calculations.

As one of the candidate for the metal-free cathode materials, the sulfur doped graphene (SG) is also reported to present high electrocatalytic activity for ORR. ${ }^{26-31}$ By replacing one $\mathrm{C}$ atom with sulfur, there are two kind of sulfur doped graphene, graphitic $S$ and thiophene S: the thiophene $S$ was found mainly at the edges of graphene bonding to $\mathrm{C},{ }^{28}$ and the graphitic $\mathrm{S}$ was found inside the lattice structure of the graphene. ${ }^{27,32}$ For ORR mechanism on the thiophene S doped graphene, Zhang et al. ${ }^{33}$ using several sulfur doped graphene clusters models demonstrated that the sulfur-doped graphene clusters with sulfur or sulfur oxide locating at graphene edges show electrocatalytic activity for ORR, and the zigzag edge or the neighboring carbon atoms of doped sulfur oxide atoms are the catalytic active sites. Summarily, from their reaction energy barrier calculation, Zhang et $a .^{33}$ predicted that the (thiophene) sulfur-doped graphene could show ORR catalytic properties comparable to Pt.

On the other hand, as other important sulfur doping configuration, the graphitic sulfur doped graphene presents the great stability from our simulations presented below. Moreover, to the best of our knowledge, the theoretical studies on the electrocatalytic activity of the graphitic sulfur doped graphene is still lack, and the detailed kinetic behaviors, the catalytic active center and the catalytic mechanism for the ORR on the graphitic sulfur doped graphene remains unclear. Thus, in the current study, we have studied the entire ORR mechanisms on the graphitic sulfur doped graphene $\left(\mathrm{SG}_{\mathrm{V}}\right)$ using the firstprinciples method. The adsorption properties for all possible 
ORR involved species and the activation energies for all possible elementary reactions of the entire ORR on the $S_{\mathrm{V}}$ in acid environment. Furthermore, the most favorable pathway for ORR on $\mathrm{SG}_{\mathrm{V}}$ is identified based on the calculation of the transition states. Our current results not only show that the ORR on $\mathrm{SG}_{\mathrm{V}}$ proceeds more possibly via a direct hydrogenation of $\mathrm{HOOH}$ reaction pathway but also demonstrate that the $\mathrm{SG}_{\mathrm{V}}$ would be an efficient metal-free electrocatalyst for ORR.

\section{Theoretical methods}

All of the spin-polarized calculations were performed within dispersion-corrected density functional theory (DFT-D) computations as implemented in $\mathrm{Dmol}^{3}$ code embedded in Materials Studio (Accelrys, SanDiego, CA). The generalized gradient approximation (GGA) with Perdew-Burke-Ernzerhof (PBE) functional was employed using the DFT semi-core pseudopotential ${ }^{34}$ with long-range dispersion correction via Grimme approach $^{35}$ to describe exchange and correlation effects, ${ }^{36}$ and the polarization p-function (DNP) as the basis set for the double numerical atomic orbital augmented was chosen. The convergence tolerances of the geometry optimization are set to $10^{-5}$ $\mathrm{Ha}(1 \mathrm{Ha}=27.21 \mathrm{eV})$ for the energy, $0.002 \mathrm{Ha} \AA^{-1}$ for the maximum force, and $0.005 \AA$ for the maximum displacement. The electronic SCF tolerance is set to $10^{-6} \mathrm{Ha}$. In order to achieve accurate electronic convergence, we apply a smearing of $0.005 \mathrm{Ha}$ to the orbital occupation. The $k$-points grid is set as 5 $\times 5 \times 1$ and the $k$-points are generated automatically using the Monkhorst-Pack method ${ }^{37}$ for the relaxation calculations. And denser meshes of $15 \times 15 \times 1$ are used to calculate the density of states (DOS) for the electronic relaxation. The transition states are obtained by linear synchronous transit (LST)/ quadratic synchronous transit (QST) method in $\mathrm{Dmol}^{3}$ code for ORR elemental steps. It is found that all the minima possess real frequencies, and the transition states have only one imaginary frequency.

Gibbs free energy of the ORR intermediates can be calculated with the approach developed by Nørskov et al. ${ }^{38}$ The change in free energy for the elemental step is defined as $\Delta G=\Delta E+\Delta \mathrm{ZPE}$ $+T \Delta S+\Delta G_{\mathrm{U}}+\Delta G_{\mathrm{PH}}+\Delta G_{\text {field }}$, where $\Delta E$ is the reaction energy based on DFT-D calculations, $\triangle \mathrm{ZPE}$ is the zero point energy, $T$ is the temperature and equal to $300 \mathrm{~K}, \Delta S$ is the change in the entropy. ZPE and $S$ of the ORR intermediates are calculated based on the vibrational frequencies. $\Delta G_{\mathrm{U}}$ are the free energy contributions due to variations in the electrode potential $U . \Delta G_{U}$ $=-n e U$, where $n$ is the number of electrons transferred and $U$ is the electrode potential $v s$. the standard hydrogen electrode (SHE). In our system, $\Delta G_{\mathrm{PH}}$ isn't discussed. $\Delta G_{\text {field }}$ is normally ignored due to its small value. ${ }^{38}$ We set the reference potential to be that of the standard hydrogen electrode. The free energy of $1 / 2 \mathrm{H}_{2}$ can be used to instead of that of $\left(\mathrm{H}^{+}+\mathrm{e}^{-}\right)$. The free energy of $\mathrm{H}_{2} \mathrm{O}$ was calculated in the gas phase at $300 \mathrm{~K}$ and the free energy of $\mathrm{O}_{2}$ was obtained from the reaction $\mathrm{O}_{2}+2 \mathrm{H}_{2}=2 \mathrm{H}_{2} \mathrm{O}$ for which a free energy change is $4.92 \mathrm{eV}^{39}$

The adsorption energy $\left(E_{\mathrm{ad}}\right)$ is defined as $E_{\text {ad }}=E_{\text {adsorbate }}+$

$E_{\text {support }}-E_{\text {adsorbate/support, }}$ where $E_{\text {adsorbate }}, E_{\text {support }}$ and $E_{\text {adsorbate/support }}$ are the total energies of the free adsorbate, the corresponding support and the support with the adsorbate, respectively. With this definition, a positive value indicates an exothermic adsorption. We use the same periodic box dimensions and the same level of calculations to obtain all the energies for $E_{\text {adsorbate }}, E_{\text {support }}$, and $E_{\text {adsorbate/support }}$.

\section{Results and discussion}

\subsection{Properties of $\mathbf{S G}_{\mathbf{V}}$}

The $\mathrm{SG}_{\mathrm{V}}$ is modeled by replacing one of the lattice carbon atoms with a $S$ atom from a $4 \times 4$ graphene supercell with the vacuum layer of $15 \AA$. According to our careful tests, the size of supercell is enough to study the ORR process. In the optimized $\mathrm{SG}_{\mathrm{V}}$ (as shown in Fig. 1a), the $S$ atom protrudes out of the graphene plane forming three S-C1 bonds of $1.47 \AA$. The $\mathrm{C} 1-\mathrm{C} 2$ bond neighboring to the $\mathrm{S}$ dopant is $1.40 \AA$ (see Fig. 1a). The formation energy $\left(E_{\mathrm{f}}\right)$ of the $\mathrm{SG}_{\mathrm{V}}$ given by $E_{\mathrm{f}}=E_{\text {total }}(m, n)-E_{\text {total }}(\mathrm{Gra})$ $-m \mu_{\mathrm{S}}+n \mu_{\mathrm{C}}$. In the formula, $E_{\text {total }}(\mathrm{S})$ is the total energy of the supercell with the defect complex, and $E_{\text {total }}(\mathrm{Gra})$ is the total energy of the pristine graphene. The symbols $\mu_{\mathrm{S}}$ and $\mu_{\mathrm{C}}$ are the chemical potentials of $\mathrm{S}$ and $\mathrm{C}$ and $m$ and $n$ is the number of $\mathrm{S}$ and the substituted $\mathrm{C}$, respectively. $\mu_{\mathrm{C}}$ is calculated as the carbon atom in the graphene. For the chemical potential of $\mathrm{S}$, which is tunable in the experiments, we set the range from $\mathrm{H}_{2} \mathrm{~S}$ to the free atomic sulfur. The $E_{\mathrm{f}}$ of the $\mathrm{S}$ doped graphene is from 3.68 to $0.45 \mathrm{eV}$. The increased $\mu_{\mathrm{S}}$ is corresponding to the decreased $E_{\mathrm{f}}$, indicating that $\mathrm{S}$ is able to dope into graphene at high $\mathrm{S}$ chemical potential. The $E_{\mathrm{f}}$ of $\mathrm{S}$ doped divacancy graphene with $\mu_{\mathrm{S}}$ of the free atomic sulfur is $1.71 \mathrm{eV}$ (higher $1.26 \mathrm{eV}$ than $\mathrm{SG}_{\mathrm{V}}$ ), because the formation of divacancy graphene is more difficult. Therefore, $\mathrm{SG}_{\mathrm{V}}$ is easier to form by thermodynamic standpoint.

To understand the introduced changes of the $\mathrm{SG}_{\mathrm{V}}$ electronic structure upon sulfur doping, the calculated DOS of the $\mathrm{SG}_{\mathrm{V}}$ and the pure graphene are presented in Fig. 1b. Different from that of pure graphene, upon sulfur doping, some sharp peaks emerges at the Fermi level of the $\mathrm{SG}_{\mathrm{v}}$. According to the partial density of states (PDOS) analysis (presented in Fig. 1c), the emerged peaks are mainly from the sulfur dopant and the its neighboring $\mathrm{C}$ atoms. As suggested in previous works, those kind of states near the Fermi level would facilitate to the charge transfer between the substrate and the adsorbed species, ${ }^{40,41}$ and the sulfur doping induced electronic states emerging near the Fermi level should play an important role in the enhanced chemical activity of graphene.

In addition to the novel catalytic activity of $\mathrm{SG}_{\mathrm{V}}$ with electronic structure analysis, on the other hand, the stability of $\mathrm{SG}_{\mathrm{V}}$ is a precondition for ORR. Fig. 2a presents the deformation charge density (DCD) map for the $\mathrm{SG}_{\mathrm{V}}$, which confirms the formation of the stable covalent bond between sulfur atom and its neighboring $\mathrm{C}$ atoms, in line with the recent experimental results. ${ }^{27}$ According to the Mulliken atomic charges analysis, the atomic $\mathrm{S}$ is negatively charged by $0.09|e|$, the atomic $\mathrm{C} 1$ is negatively charged by $0.06|e|$ and the atomic $\mathrm{C} 2$ is positively charged by $0.06|e|$, indicating a negligible charge transfer between the S and graphene sheet, due to the similar electronegativity of $\mathrm{S}$ and $\mathrm{C}$. 


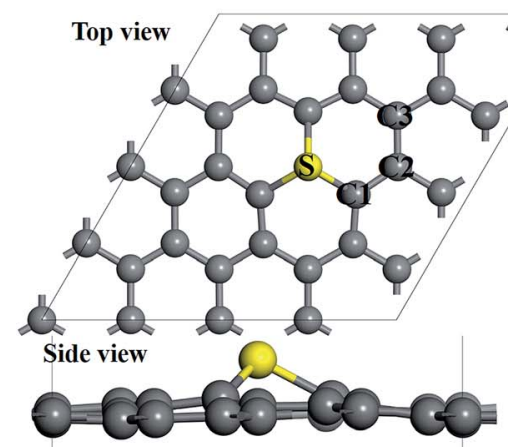

(a)

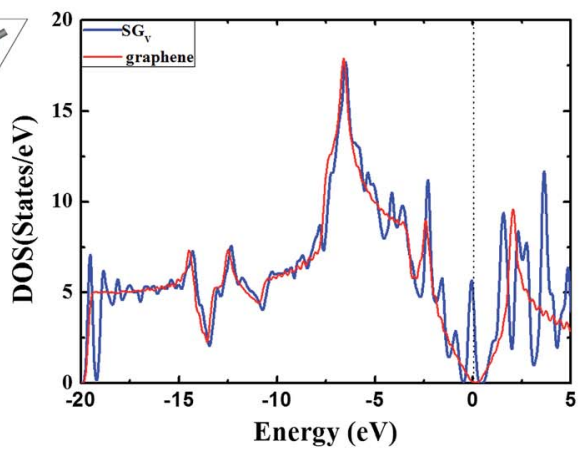

(b)

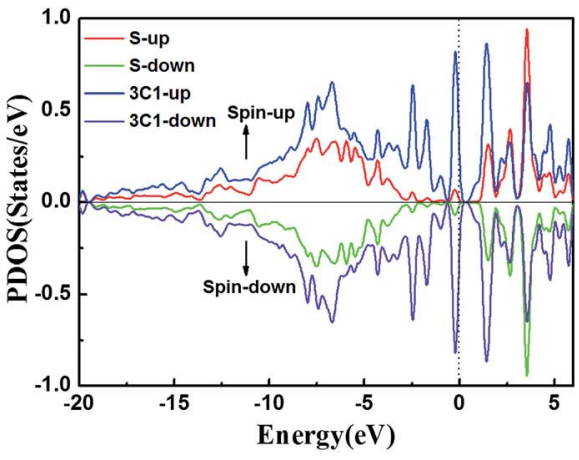

(c)

Fig. 1 (a) Top and side views of the most stable configurations of sulfur doped monovacancy graphene (SGV), the carbon atoms near the sulfur atom are marked as "C1", "C2", and "C3", respectively. Hereafter, the gray and yellow spheres represent C and S atoms, respectively. (b) The density of states (DOS) for the SG and pure graphene. (c) The partial density of states (PDOS) for S and three "C1" atoms of SGv. The Fermi level is indicated with a black dotted line.

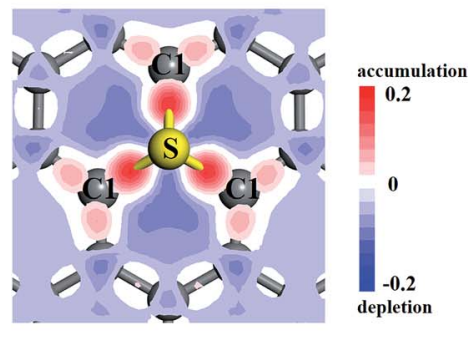

(a)

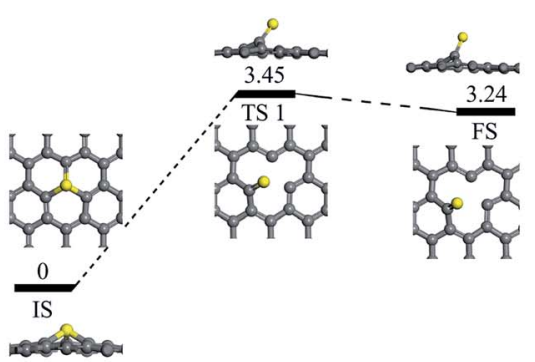

(b)

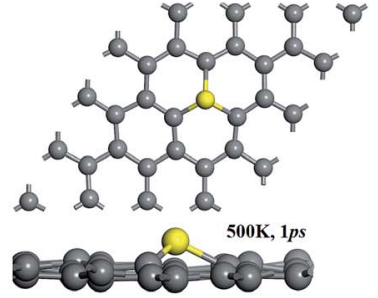

(c)

Fig. 2 (a) Deformation charge density (DCD) map in the SG plane, which displays the charge density overlap between the atomic sulfur and its neighboring atomic carbon. Blue, white and red represent charges depletion, non-transition and accumulation. (b) Optimized structures for the initial states (IS), the transition states (TS), and the final states (FS) (side view and top view) along the diffusion pathway of sulfur from the most stable configuration to the second most stable configuration. (c) The final SG structure from the molecular dynamics simulation at $500 \mathrm{~K}$.

The stability of the $\mathrm{SG}_{\mathrm{V}}$ model is further investigated from the mobility of the doping $\mathrm{S}$ and diffusion of the $\mathrm{S}$ dopant to its neighbor stable adsorption site. The various configurations of the $\mathrm{S}$ doped graphene or the adsorption of the $\mathrm{S}$ atom on the monovacancy-graphene support are presented in Fig. S1 in the $\mathrm{ESI}, \dagger$ and it is turned out that $\mathrm{SG}_{\mathrm{V}}$ presented above is the most stable configuration from the rather strong interaction between the $\mathrm{S}$ atom and the defect-graphene support. The $\mathrm{S}$ atom adsorbed on one of $\mathrm{C}$ atoms around the defect is the second most stable configuration (see Fig. $\mathrm{S} 1 \dagger$ and $2 \mathrm{~b}$ ). The extremely big diffusion barrier (marked as "TS 1" in Fig. 2b) of $3.45 \mathrm{eV}$ for the mobility of the $\mathrm{S}$ dopant from the most stable adsorption configuration (the selected $\mathrm{SG}_{\mathrm{V}}$ model) to the second most stable adsorption configuration indicates the immobility of the atomic $\mathrm{S}$ anchored at the monovacancy-graphene and the great stability of the selected $\mathrm{SG}_{\mathrm{V}}$ model. To further confirm the thermodynamical stable of $\mathrm{SG}_{\mathrm{V}}$, the first principles molecular dynamics calculations are performed in a period of $1000 \mathrm{fs}$ at the temperature of $500 \mathrm{~K}$. The final structure of $\mathrm{SG}_{\mathrm{V}}$ from the molecular dynamics calculations is presented in Fig. 2 c, and it is turned out that the $\mathrm{C}$ and $\mathrm{S}$ atoms are almost in the same plane just with slight distortion.

\subsection{The adsorption of various $\mathbf{O R R}$ involved species on $\mathbf{S G}_{\mathbf{V}}$}

The most stable configurations of the various ORR involved species on $\mathrm{SG}_{\mathrm{V}}$, including $\mathrm{O}_{2}, \mathrm{OOH}, \mathrm{HOOH}, \mathrm{O}, \mathrm{H}, \mathrm{OH}$, and $\mathrm{H}_{2} \mathrm{O}$, are presented in Fig. 3, and their corresponding adsorption properties are summarized in Table 1.

The adsorption of $\mathrm{O}_{2}$ is a prerequisite of the ORR proceeding on the catalyst, thus we firstly investigate the adsorption characters of $\mathrm{O}_{2}$. The most stable adsorption configuration of an $\mathrm{O}_{2}$ molecule is on a carbon (marked as "C2") site with the $E_{\text {ad }}$ of $0.25 \mathrm{eV}$, the $\mathrm{O}-\mathrm{O}$ bond length of $1.24 \AA$ and the $\mathrm{O}$ and $\mathrm{C} 2$ distance of $3.17 \AA$ (see Fig. 3a). Given the weak interaction together with the negligible charge transfer between the $\mathrm{O}_{2}$ molecule and the $\mathrm{SG}_{\mathrm{V}}$ support, this adsorption configuration (presented in Fig. 3a) would be a physisorption configuration without the formation of the chemical bond between $\mathrm{O}_{2}$ molecule and the $\mathrm{SG}_{\mathrm{V}}$ support.

The co-adsorption of $\mathrm{O}_{2}$ and $\mathrm{H}^{*}$ (hereafter, "*” represents the reactant binding to the support) is an important intermediate product, where the $\mathrm{O}_{2}$ (the $\mathrm{O}-\mathrm{O}$ bond of $1.29 \AA$ ) and $\mathrm{H}^{*}$ is respectively adsorbed on the hollow site and the $\mathrm{C} 1$ site forming a C-H bond of $1.13 \AA$ (see Fig. 3b). The $E_{\text {ad }}$ of $\mathrm{O}_{2}$ and $\mathrm{H}^{*}$ is $0.11 \mathrm{eV}$ and $1.64 \mathrm{eV}$, respectively. The adsorbed $\mathrm{O}_{2}$ is negatively charged by $0.32|e|$, and the $\mathrm{H}^{*}$ is positively charged by $0.24|e|$. 


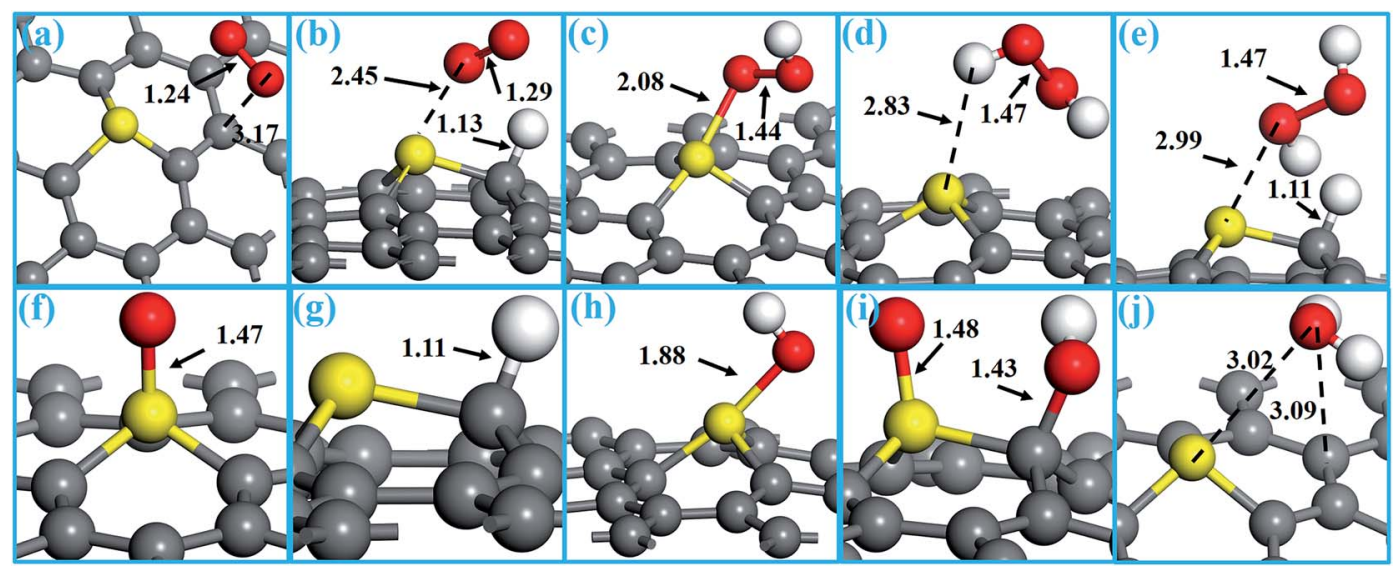

Fig. 3 The relaxed structures for the various ORR involved species adsorbed on SGv: (a) $\mathrm{O}_{2}$, (b) $\mathrm{O}_{2}+\mathrm{H}^{*}$, (c) $\mathrm{OOH}^{*}$, (d) $\mathrm{HOOH}$, (e) $\mathrm{HOOH}+\mathrm{H}^{*}$, (f) $\mathrm{O}^{*}$, (g) $\mathrm{H}^{*}$, (h) $\mathrm{OH}^{*}$, (i) $\mathrm{O}^{*}+\mathrm{OH}^{*}$, (j) $\mathrm{H}_{2} \mathrm{O}$. Hereafter, red and white spheres represent $\mathrm{O}$ and $\mathrm{H}$ atoms, respectively.

It is found that the $\mathrm{OOH}$ species prefers to adsorb on sulfur dopant with the formation of the $\mathrm{O}-\mathrm{S}$ bond of $2.08 \AA$ (see Fig. 3c), and the $\mathrm{O}-\mathrm{O}$ bond of the adsorbed $\mathrm{OOH}$ is $1.44 \AA$ and the $\mathrm{O}-\mathrm{H}$ bond is $0.98 \AA$. The $E_{\text {ad }}$ of $\mathrm{OOH}^{*}$ is $0.66 \mathrm{eV}$ and the $\mathrm{OOH}^{*}$ is negatively charged by $0.29|e|$. The $\mathrm{HOOH}$ specie weakly adsorbs on $\mathrm{SG}_{\mathrm{V}}$ with the small $E_{\mathrm{ad}}$ of $0.34 \mathrm{eV}$ and the negligible charge transfer $(0.03|e|)$, and the distance between $\mathrm{H}$ and $\mathrm{S}$ is $2.83 \AA$ (see Fig. 3d).

As one of the intermediate products, the most stable coadsorption configuration of the $\mathrm{HOOH}$ and $\mathrm{H}^{*}$ is presented in Fig. 3e: the $\mathrm{HOOH}$ stays above the sulfur dopant, and the $\mathrm{H}^{*}$ adsorbed on C1 forming a C-H bond of $1.11 \AA$. The $E_{\text {ad }}$ of $\mathrm{HOOH}$ and $\mathrm{H}^{*}$ is $0.49 \mathrm{eV}$ and $1.94 \mathrm{eV}$, respectively. The adsorbed $\mathrm{HOOH}$ is negatively charged by $0.03|e|$. The $\mathrm{H}^{*}$ is positively charged by $0.21|e|$.

As another ORR reactant, the atomic $\mathrm{O}$ is preferably adsorbed on S site with the rather big $E_{\text {ad }}$ of $5.06 \mathrm{eV}$, and the length of the formed S-O bond is $1.47 \AA$ (see Fig. 3d). The atomic $\mathrm{O}$ is

Table 1 The corresponding adsorption configurations, adsorption energies $\left(E_{\mathrm{ad}}\right.$ in $\left.\mathrm{eV}\right)$ and Mulliken charges $(\Delta q$ in $|e|)$ are summarized. Geometric and energetic parameters of reaction intermediates as identified in the stable state ${ }^{a}$

\begin{tabular}{llllr}
$\begin{array}{l}\text { Reaction } \\
\text { intermediates }\end{array}$ & Configurations & Bond lengths $(\AA)$ & $E_{\text {ad }}$ & \multicolumn{1}{c}{$\Delta q$} \\
\hline $\mathrm{O}_{2}$ & Top-C2 & $\mathrm{d}(\mathrm{O}-\mathrm{O})=1.24$ & 0.25 & -0.21 \\
$\mathrm{O}_{2}+\mathrm{H}^{*}$ & Hollow & $\mathrm{d}(\mathrm{O}-\mathrm{O})=1.29$ & 0.11 & -0.32 \\
& & $\mathrm{~d}(\mathrm{H}-\mathrm{C})=1.13$ & 1.64 & 0.24 \\
$\mathrm{OOH}^{*}$ & Hollow & $\mathrm{d}(\mathrm{O}-\mathrm{O})=1.44$ & 0.66 & -0.29 \\
$\mathrm{HOOH}$ & Hollow & $\mathrm{d}(\mathrm{O}-\mathrm{O})=1.47$ & 0.34 & 0.03 \\
$\mathrm{HOOH}+\mathrm{H}^{*}$ & Hollow & $\mathrm{d}(\mathrm{O}-\mathrm{O})=1.47$ & 0.49 & 0.03 \\
& & $\mathrm{~d}(\mathrm{H}-\mathrm{C})=1.11$ & 1.94 & 0.21 \\
$\mathrm{O}^{*}$ & Top-S & $\mathrm{d}(\mathrm{O}-\mathrm{S})=1.47$ & 5.06 & -0.35 \\
$\mathrm{H}^{*}$ & Top-C1 & $\mathrm{d}(\mathrm{H}-\mathrm{C})=1.11$ & 1.78 & 0.17 \\
$\mathrm{OH}^{*}$ & Top-S & $\mathrm{d}(\mathrm{O}-\mathrm{S})=1.88$ & 1.79 & -0.27 \\
$\mathrm{O}^{*}+\mathrm{OH}^{*}$ & Top-S & $\mathrm{d}(\mathrm{O}-\mathrm{S})=1.48$ & 4.49 & -0.35 \\
& Top-C1 & $\mathrm{d}(\mathrm{O}-\mathrm{C})=1.43$ & 1.22 & -0.09 \\
$\mathrm{H}_{2} \mathrm{O}$ & Hollow & $\mathrm{d}(\mathrm{O}-\mathrm{H})=0.97$ & 0.35 & 0.04
\end{tabular}

$a *$ represented that the reactant binds to the $\mathrm{SG}_{\mathrm{V}}$ surface. negatively charged by $0.35|e|$. The atomic $\mathrm{H}$ prefers to adsorb on $\mathrm{C} 1$ site (neighboring the $\mathrm{S}$ dopant) with an $E_{\mathrm{ad}}$ of $1.78 \mathrm{eV}$, and the formed $\mathrm{C}-\mathrm{H}$ bond is $1.11 \AA$ (see Fig. $3 \mathrm{~g}$ ). The atomic $\mathrm{H}$ is positively charged by $0.17|e|$, confirming that $\mathrm{H}^{*}$ could be taken as $\mathrm{H}^{+}$in the calculations.

As an important intermediate product, $\mathrm{OH}$ is preferably adsorbed on S site forming an S-O bond of $1.88 \AA$ with an $E_{\text {ad }}$ of $1.79 \mathrm{eV}$ (see Fig. 3h). The $\mathrm{OH}^{*}$ is negatively charged by $0.27|e|$. The co-adsorption of $\mathrm{O}$ and $\mathrm{OH}$ is other important intermediate product, where the $\mathrm{O}$ and $\mathrm{OH}$ adsorbs on the $\mathrm{S}$ site and the $\mathrm{C} 1$ site forming an $\mathrm{S}-\mathrm{O}$ bond of $1.48 \AA$ and a $\mathrm{C}-\mathrm{O}$ bond of $1.43 \AA$, respectively (see Fig. 3i).

As the final product, $\mathrm{H}_{2} \mathrm{O}$ is weakly adsorbed on the $\mathrm{SG}_{\mathrm{V}}$ with the small adsorption energy of $0.35 \mathrm{eV}$ (see Fig. 3j). The weak adsorption together with the long distance and the negligible charge transfer between $\mathrm{H}_{2} \mathrm{O}$ and the $\mathrm{SG}_{\mathrm{V}}$ support indicates that the formed $\mathrm{H}_{2} \mathrm{O}$ would be easily released as the final product of ORR.

\subsection{Chemical behavior in various reaction pathways}

As mentioned above, it is found that the rather stronger adsorption of $\mathrm{H}$ than the $\mathrm{O}_{2}(1.78 \mathrm{eV}$ vs. $0.25 \mathrm{eV})$, and the adsorption of $\mathrm{H}$ is greatly preferable than $\mathrm{O}_{2}$. Thus, the direct dissociation pathway of the adsorbed $\mathrm{O}_{2}$ on $\mathrm{SG}_{\mathrm{V}}$ support would not be further considered in here, and the $\mathrm{H}$ pro-adsorbed configuration would be focused. As shown in Fig. 4, it is found that the weakly adsorbed $\mathrm{O}_{2}$ is easily hydrogenated by the pre-adsorbed $\mathrm{H}$ into $\mathrm{OOH}^{*}$ on $\mathrm{SG}_{\mathrm{V}}$ : firstly, the $\mathrm{O}_{2}+\mathrm{H}^{*}$ coadsorbed configuration would form the metastable state (MS) of $\mathrm{OOH}^{*}$ with a reaction barrier of $0.39 \mathrm{eV}$ and an exothermic reaction energy of $0.78 \mathrm{eV}$. Then the metastable adsorbed $\mathrm{OOH}^{*}$ convert into the most stable adsorbed $\mathrm{OOH}^{*}$ with a small reaction barrier of $0.18 \mathrm{eV}$ and a slight exothermic reaction energy of $0.02 \mathrm{eV}$. The most stable adsorbed $\mathrm{OOH}^{*}$ is dissociated into the metastable co-adsorbed $\mathrm{O}+\mathrm{OH}$ species via the activation barrier of $0.44 \mathrm{eV}$ and an exothermic reaction energy of $1.17 \mathrm{eV}$. Finally, the formed $\mathrm{OH}^{*}$ would diffuse from $\mathrm{S}$ site to $\mathrm{C} 1$ site via the diffusion barrier of $0.75 \mathrm{eV}$ and an exothermic 


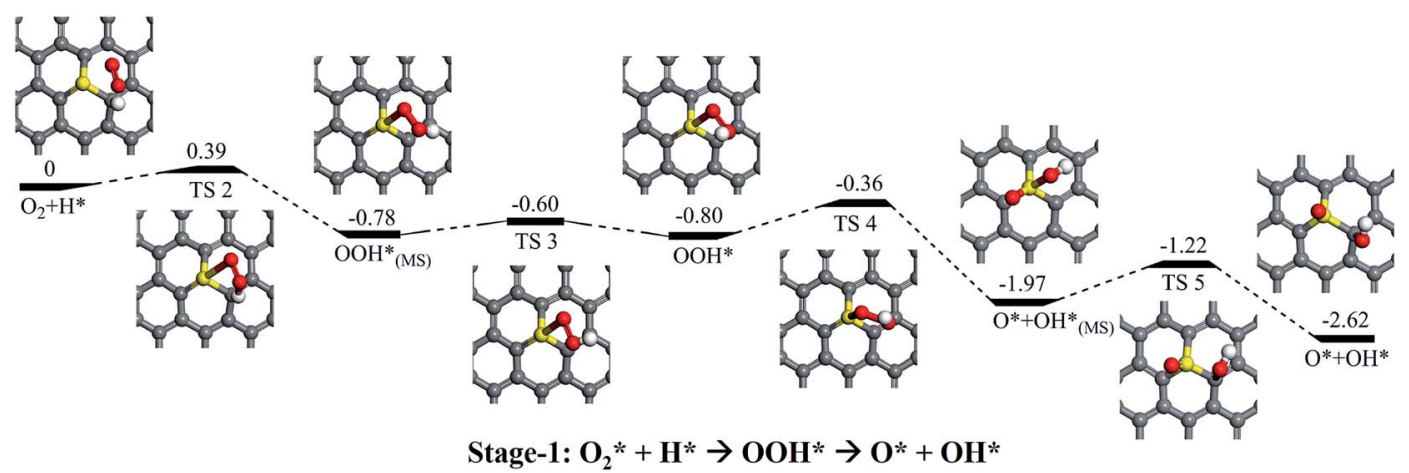

Fig. 4 Schematic potential energy profiles for the formation of $\mathrm{OOH}^{*}$ and the direct dissociation of OOH* on $\mathrm{SG}_{V}$ (Stage-1). The calculated transition states (TS) are denoted as "TS 2", "TS 3", "TS 4" and "TS 5", respectively and the metastable state is denoted as MS.

reaction energy of $0.65 \mathrm{eV}$. The above process is marked as Stage-1.

In addition to the direct $\mathrm{OOH}^{*}$ dissociation pathway, the hydrogenation of $\mathrm{OOH}^{*}$ species is also considered, and the corresponding process is noted as "Stage-2" in Fig. 5. In Stage-2, upon the hydrogenation of the $\mathrm{OOH}^{*}$ species by the coadsorbed $\mathrm{H}^{*}$, the $\mathrm{HOOH}$ is formed via a reaction barrier of $0.53 \mathrm{eV}$ and an exothermic reaction energy of $1.23 \mathrm{eV}$. We find that the formed $\mathrm{HOOH}$ is difficultly dissociated into two $\mathrm{OH}$ species due to the weak adsorption of $\mathrm{HOOH}$ on $\mathrm{SG}_{\mathrm{V}}$. "Stage-3" in Fig. 5 is presented the hydrogenation of the $\mathrm{HOOH}$ by the coadsorbed $\mathrm{H}^{*}$ : the co-adsorbed $\mathrm{OH}^{*}+\mathrm{H}_{2} \mathrm{O}$ is formed via a reaction barrier of $0.36 \mathrm{eV}$ and an exothermic reaction energy of $2.70 \mathrm{eV}$. As mentioned above, the formed $\mathrm{H}_{2} \mathrm{O}$ would easily release due to the weak interaction between $\mathrm{H}_{2} \mathrm{O}$ and $\mathrm{SG}_{\mathrm{V}}$.

Following the formation of the $\mathrm{O}^{*}+\mathrm{OH}^{*}$ species from the dissociation of $\mathrm{OOH}^{*}$, there are two possible pathways for their further hydrogenation: the $\mathrm{O}^{*}$ hydrogenation or the $\mathrm{OH}^{*}$ hydrogenation. On the one hand, we found that the hydrogenation of the $\mathrm{OH}$ would result in the formation of $\mathrm{H}_{2} \mathrm{O}$ via a reaction barrier of $0.68 \mathrm{eV}$ and an exothermic reaction energy of $3.28 \mathrm{eV}$, respectively (see Stage-4 in Fig. 6). As the final product of the ORR process, the $\mathrm{H}_{2} \mathrm{O}$ molecule would be easily released due to the week interaction between $\mathrm{H}_{2} \mathrm{O}$ and $\mathrm{SG}_{\mathrm{V}}$ (with an adsorbed atomic O), which has a rather small $E_{\text {ad }}$ of $0.39 \mathrm{eV}$.

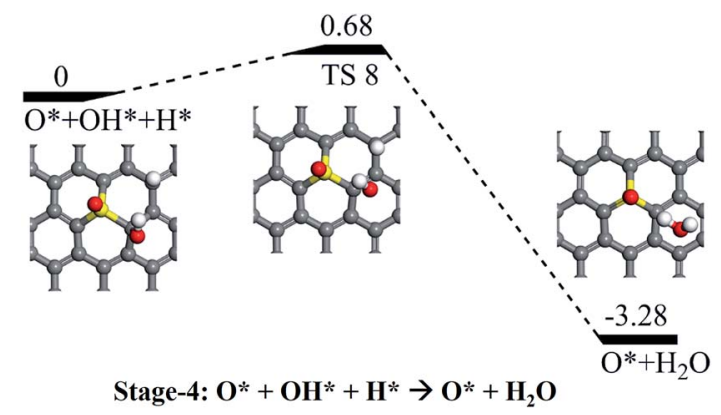

Fig. 6 Schematic potential energy profiles for the formation of the $\mathrm{H}_{2} \mathrm{O}$ from the hydrogenation of the $\mathrm{OH}$ (Stage-4). The corresponding TS is denoted as "TS 8".

On the other hand, the hydrogenation of the $\mathrm{O}^{*}$ of the coadsorbed $\mathrm{O}^{*}+\mathrm{OH}^{*}$ is difficult because of the rather high reaction barrier $(2.77 \mathrm{eV})$, and the pathway is not further considered.

Following the release of the (first) formed $\mathrm{H}_{2} \mathrm{O}$ molecule, the left atomic $\mathrm{O}$ staying on sulfur will be hydrogenated into the $\mathrm{OH}$ species via a reaction barrier of $0.40 \mathrm{eV}$ and an exothermic reaction energy of $0.19 \mathrm{eV}$ (see Stage-5 in Fig. 7). Again, the formed $\mathrm{OH}$ would be further hydrogenated into $\mathrm{H}_{2} \mathrm{O}$ via the reaction barrier of $0.62 \mathrm{eV}$ and an exothermic reaction energy of

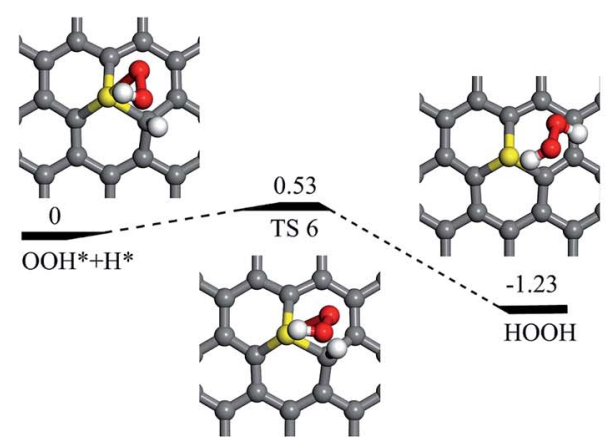

Stage-2: $\mathrm{OOH}^{*}+\mathrm{H}^{*} \rightarrow \mathrm{HOOH}^{*}$

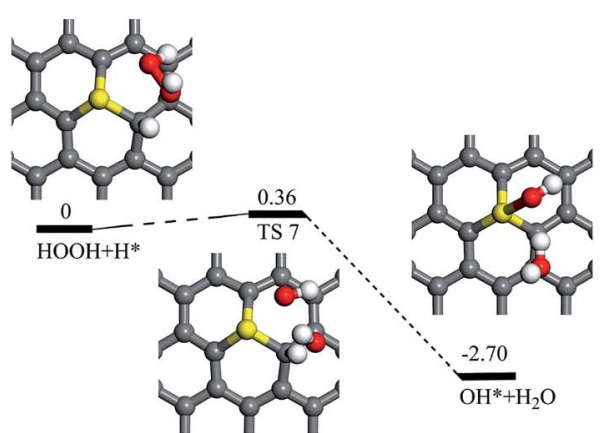

Stage-3: $\mathrm{HOOH}+\mathrm{H}^{*} \rightarrow \mathrm{OH}^{*}+\mathrm{H}_{2} \mathrm{O}$

Fig. 5 Schematic potential energy profiles for the hydrogenation of $\mathrm{OOH}^{*}$ (Stage-2), and the hydrogenation of $\mathrm{HOOH}$ (Stage-3). The corresponding TS are denoted as "TS 6" in Stage-2 and "TS 7" in Stage-3, respectively. 


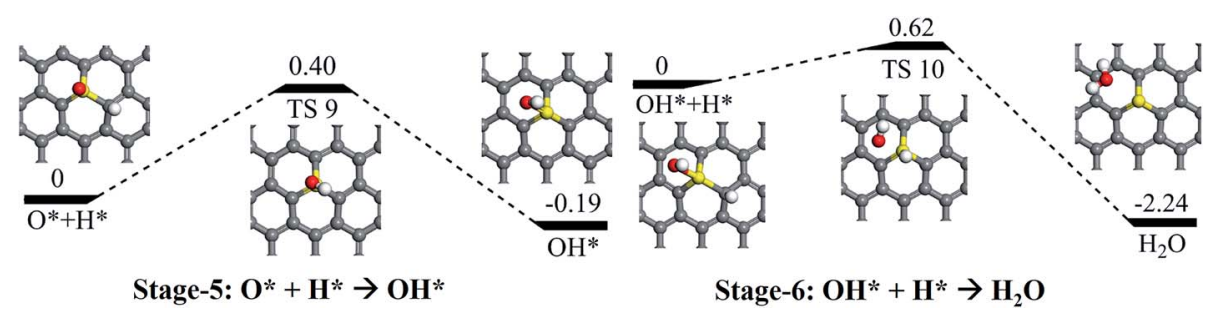

Fig. 7 Schematic potential energy profiles for the formation of the $\mathrm{OH}$ species from the hydrogenation of the atomic $\mathrm{O}(\mathrm{Stage}-5)$ and the (second) $\mathrm{H}_{2} \mathrm{O}$ formation from the hydrogenation of the OH (Stage-6). The corresponding TS are denoted as "TS 9" in Stage-5 and "TS 10" in Stage-6, respectively.

$2.24 \mathrm{eV}$ (see Stage-6 in Fig. 7). The formed $\mathrm{H}_{2} \mathrm{O}$ would easily release due to the weak interaction between water and the support, resulting in the recovery of $\mathrm{SG}_{\mathrm{V}}$.

\subsection{The selectivity of two pathways with kinetics and thermodynamics}

According to the reaction stages presented above, two possible pathways are proposed for the entire ORR process on $\mathrm{SG}_{\mathrm{V}}$, which are summarized in Fig. 8a.

Pathway I: Stage- 1 (to form O $+\mathrm{OH}$ ) $\rightarrow$ Stage- $4 \rightarrow$ Stage- $5 \rightarrow$ Stage-6

Pathway II: Stage- 1 (to form OOH) $\rightarrow$ Stage- $2 \rightarrow$ Stage- $3 \rightarrow$ Stage-6

In pathway I (black lines in Fig. 8), the pathway starts from the direct hydrogenation of the adsorbed $\mathrm{O}_{2}$, resulting in the formation of the $\mathrm{OOH}^{*}$ species. The form $\mathrm{OOH}^{*}$ is dissociated into $\mathrm{O}^{*}+\mathrm{OH}^{*}$. Upon a diffusion process, the formed $\mathrm{O}^{*}$ and
$\mathrm{OH}^{*}$ would be further hydrogenated into $\mathrm{H}_{2} \mathrm{O}$. The ratedetermining step of pathway I is the diffusion of $\mathrm{OH}^{*}$ and the corresponding reaction barrier is $0.75 \mathrm{eV}$.

In pathway II (red lines in Fig. 8), the pathway starts from the co-adsorption of $\mathrm{O}_{2}+\mathrm{H}^{*}$. The $\mathrm{O}_{2}$ will proceed with three sequential hydrogenation reactions to form $\mathrm{OOH}^{*}, \mathrm{HOOH}$ and the final ORR product of released $\mathrm{H}_{2} \mathrm{O}$ molecule, whereas the left $\mathrm{OH}^{*}$ is chemisorbed on sulfur. Finally, the $\mathrm{OH}^{*}$ is hydrogenated into the second $\mathrm{H}_{2} \mathrm{O}$. The rate-determining step of this pathway is the formation of the second $\mathrm{H}_{2} \mathrm{O}$ with a reaction barrier of $0.62 \mathrm{eV}$.

According to the computed free energy diagram, all of the reduction steps of pathway I and pathway II are presented in Fig. $8 \mathrm{~b}$ and $\mathrm{c}$, respectively. In pathway I, all of the reduction steps except the $\mathrm{O}$ reduction are downhill at 0 potential, as shown in Fig. 8b. The reduction step of $\mathrm{O}$ into $\mathrm{OH}$ has a positive $\Delta G$ of $0.86 \mathrm{~V}$ at 0 potential, which is the thermodynamic rate-determining step. When the thermodynamic process is

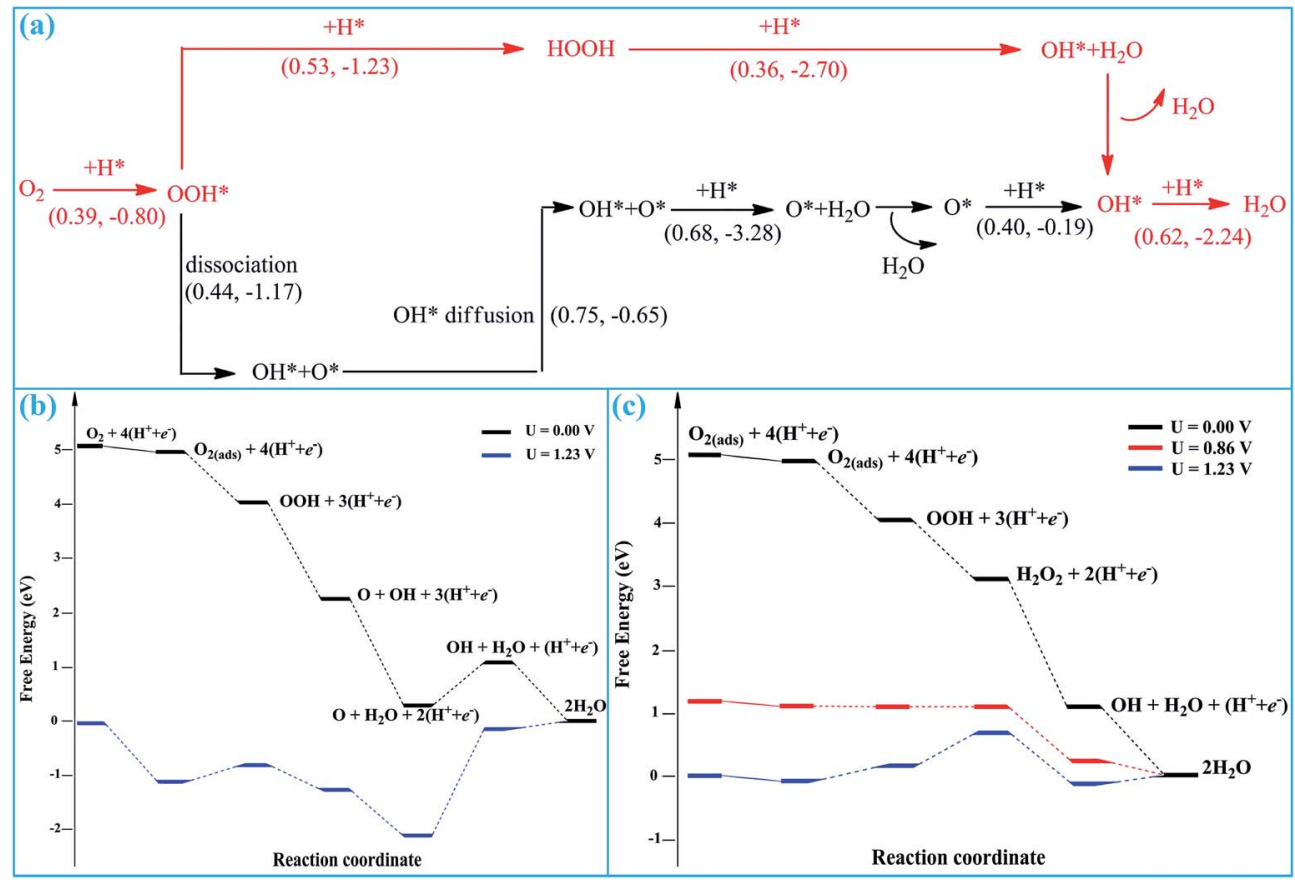

Fig. 8 (a) Proposed pathways for the entire ORR process on SG. The most favorable reaction pathway is expressed as red lines. The activation and reaction energies (in eV) are given in parentheses in the form of "(TS, $\Delta E$ )", accordingly. Free-energy diagram for ORR along (b) pathway I and (c) pathway II in on the SGV, the subscript (ads) represents the adsorption on the SGV. 
continuously exothermic, it can be favorably applicable to ORR. Therefore, pathway I is precluded by the Gibbs free energy calculation, because the process of reduction step of $\mathrm{O}$ into $\mathrm{OH}$ is endothermic at 0 potential. However, in pathway II, all of the reduction steps are downhill at 0 potential, indicating that the enter ORR process successfully occurs by thermodynamic calculations. And even the ORR process occurs at the high potential of $0.86 \mathrm{~V}$. Therefore, the pathway II is the most possible for ORR on $\mathrm{SG}_{\mathrm{V}}$.

\section{Conclusions}

DFT-D calculation is performed to investigate the detailed kinetic and thermodynamic behaviors of the entire ORR process on $\mathrm{SG}_{\mathrm{V}}$. It is found that the $\mathrm{SG}_{\mathrm{V}}$ is rather stable due to the strong interaction between the sulfur and the defected-graphene. The $\mathrm{O}_{2}$ molecule prefers to form $\mathrm{OOH}^{*}$ species on $\mathrm{SG}_{\mathrm{V}}$ with the coadsorbed $\mathrm{H}^{*}$. There are two proposed pathways for the entire ORR process on $\mathrm{SG}_{\mathrm{V}}$, i.e., the $\mathrm{OOH}^{*}$ direct dissociation pathway and the $\mathrm{OOH}^{*}$ hydrogenation pathway. The reaction barriers of the corresponding rate-determining steps of the two proposed pathways are $0.75 \mathrm{eV}$ and $0.62 \mathrm{eV}$, respectively. According to the Gibbs free energy simulation at various potentials, the process of the $\mathrm{OOH}$ dissociation pathway is precluded, because the process of reduction step of $\mathrm{O}$ into $\mathrm{OH}$ is endothermic. While the process of the hydrogenation of $\mathrm{HOOH}$ species is effective at 0 potential, and it can occurs at a high potential of $0.86 \mathrm{~V}$. It is expected that the $\mathrm{SG}_{\mathrm{V}}$ would be an efficient metal-free electrocatalyst for ORR.

\section{Acknowledgements}

This work is supported by the National Natural Science Foundation of China (Grant No. 51401078, 11147006, and U1404216). Sponsored by Program for Science \& Technology Innovation Talents in Universities of Henan Province (Grant No. 15HASTIT016), Foundation for the key Young Teachers of Henan Province and Key Technology Research and Development Program of Henan Province(Grant No. 152102210083 and 142102210455), Science Foundation for the Excellent Youth Scholars of Henan Normal University (Grant No. 14YQ005). Supported by The High Performance Computing Center of Henan Normal University. We are also grateful to the Computing Center of Jilin Province for essential support.

\section{References}

1 B. C. Steele and A. Heinzel, Nature, 2001, 414, 345-352.

2 R. Borup, J. Meyers, B. Pivovar, Y. S. Kim, R. Mukundan, N. Garland, D. Myers, M. Wilson, F. Garzon and D. Wood, Chem. Rev., 2007, 107, 3904-3951.

3 B. Lim, M. Jiang, P. H. Camargo, E. C. Cho, J. Tao, X. Lu, Y. Zhu and Y. Xia, Science, 2009, 324, 1302-1305.

4 F. Jaouen, E. Proietti, M. Lefèvre, R. Chenitz, J.-P. Dodelet, G. Wu, H. T. Chung, C. M. Johnston and P. Zelenay, Energy Environ. Sci., 2011, 4, 114-130.

5 R. Bashyam and P. Zelenay, Nature, 2006, 443, 63-66.
6 D. Yu, E. Nagelli, F. Du and L. Dai, J. Phys. Chem. Lett., 2010, 1, 2165-2173.

7 Y. Zheng, Y. Jiao, J. Chen, J. Liu, J. Liang, A. Du, W. Zhang, Z. Zhu, S. C. Smith, M. Jaroniec, G. Q. Lu and S. Z. Qiao, J. Am. Chem. Soc., 2011, 133, 20116-20119.

8 Z. Yang, H. Nie, X. A. Chen, X. Chen and S. Huang, J. Power Sources, 2013, 236, 238-249.

9 Z. Lu, S. Li, D. Ma, Y. Zhang, X. Yang, C. He, X. Wang and Z. Yang, J. Mater. Sci., 2016, 51, 10400-10407.

10 R. Ma, Y. Ma, Y. Dong and J.-M. Lee, Nano Adv., 2016, 1, 5061.

11 J.-i. Ozaki, S.-i. Tanifuji, A. Furuichi and K. Yabutsuka, Electrochim. Acta, 2010, 55, 1864-1871.

12 L. Qu, Y. Liu, J.-B. Baek and L. Dai, ACS Nano, 2010, 4, 13211326.

13 Z. Liu, F. Peng, H. Wang, H. Yu, J. Tan and L. Zhu, Catal. Commun., 2011, 16, 35-38.

14 D.-S. Yang, D. Bhattacharjya, S. Inamdar, J. Park and J.-S. Yu, J. Am. Chem. Soc., 2012, 134, 16127-16130.

15 C. H. Choi, S. H. Park and S. I. Woo, J. Mater. Chem., 2012, 22, 12107-12115.

16 C. H. Choi, M. W. Chung, S. H. Park and S. I. Woo, Phys. Chem. Chem. Phys., 2013, 15, 1802-1805.

17 Y. Zhao, L. Yang, S. Chen, X. Wang, Y. Ma, Q. Wu, Y. Jiang, W. Qian and Z. Hu, J. Am. Chem. Soc., 2013, 135, 12011204.

18 X. Zhang, Z. Lu, Z. Fu, Y. Tang, D. Ma and Z. Yang, J. Power Sources, 2015, 276, 222-229.

19 X. Bai, E. Zhao, K. Li, Y. Wang, M. Jiao, F. He, X. Sun, H. Sun and Z. Wu, Carbon, 2016, 105, 214-223.

20 L. Zhang and Z. Xia, J. Phys. Chem. C, 2011, 115, 1117011176.

21 S. Ni, Z. Li and J. Yang, Nanoscale, 2012, 4, 1184-1189.

22 G. Fazio, L. Ferrighi and C. Di Valentin, J. Catal., 2014, 318, 203-210.

23 Z. Lu, G. Xu, C. He, T. Wang, L. Yang, Z. Yang and D. Ma, Carbon, 2015, 84, 500-508.

24 S. Kattel and G. Wang, J. Phys. Chem. Lett., 2014, 5, 452-456.

25 J. Zhang, Z. Wang and Z. Zhu, J. Power Sources, 2014, 255, 6569.

26 Z. Yang, Z. Yao, G. Li, G. Fang, H. Nie, Z. Liu, X. Zhou, X. A. Chen and S. Huang, ACS Nano, 2011, 6, 205-211.

27 H. L. Poh, P. Šimek, Z. K. Sofer and M. Pumera, ACS Nano, 2013, 7, 5262-5272.

28 W. Kiciński, M. Szala and M. Bystrzejewski, Carbon, 2014, 68, 1-32.

29 S. Inamdar, H.-S. Choi, P. Wang, M. Y. Song and J.-S. Yu, Electrochem. Commun., 2013, 30, 9-12.

30 Z. Ma, S. Dou, A. Shen, L. Tao, L. Dai and S. Wang, Angew. Chem., 2015, 127, 1908-1912.

31 J. Wang, R. Ma, Z. Zhou, G. Liu and Q. Liu, Sci. Rep., 2015, 5, 9304.

32 D. Higgins, M. A. Hoque, M. H. Seo, R. Wang, F. Hassan, J.-Y. Choi, M. Pritzker, A. Yu, J. Zhang and Z. Chen, Adv. Funct. Mater., 2014, 24, 4325-4336.

33 L. Zhang, J. Niu, M. Li and Z. Xia, J. Phys. Chem. C, 2014, 118, 3545-3553. 
34 B. Delley, Phys. Rev. B: Condens. Matter Mater. Phys., 2002, 66, 155125.

35 B. Delley, J. Chem. Phys., 1990, 92, 508-517.

36 J. P. Perdew, K. Burke and M. Ernzerhof, Phys. Rev. Lett., 1996, 77, 3865.

37 H. J. Monkhorst and J. D. Pack, Phys. Rev. B: Solid State, 1976, 13, 5188 .
38 J. K. Nørskov, J. Rossmeisl, A. Logadottir, L. Lindqvist, J. R. Kitchin, T. Bligaard and H. Jonsson, J. Phys. Chem. B, 2004, 108, 17886-17892.

39 J. Zhang, L. Liu, W. Liu and M. Zhang, J. Electrochem. Soc., 2016, 163, F160-F165.

40 X. Fan, W. Zheng and J.-L. Kuo, RSC Adv., 2013, 3, 5498-5505. 41 Y. Tang, Z. Yang, X. Dai, D. Ma and Z. Fu, J. Phys. Chem. C, 2013, 117, 5258-5268. 